\title{
Time-Resolved In Situ Diffraction Study of the Solvothermal Crystallization of Some Prototypical Metal-Organic Frameworks**
}

\author{
Franck Millange, * Manuela I. Medina, Nathalie Guillou, Gérard Férey, Kathryn M. Golden, and \\ Richard I. Walton*
}

The crystallization of metal-organic framework (MOF) materials ${ }^{[1]}$ is an extremely attractive way in which to produce functional solid materials with complex three-dimensional structures, since an element of "design" is considered possible in their synthesis: the idea being that by using chosen metal polyhedral units linked by polydentate organic ligands with a known coordination preference, a network structure of desired connectivity may be formed. ${ }^{[2,3]}$ This synthetic approach is presently the focus of some considerable attention and is yielding many novel hybrid inorganic-organic solids, often that possess some porosity on the nanoscale suitable for applications, such as gas separation, molecular sieving, and shape-selective catalysis. ${ }^{[4]}$ Although these uses are already well-established in silicate zeolite chemistry, there are distinct advantages offered by the MOFs for uses under mild conditions. For example, the choice of framework metal may offer desirable binding sites for gases (currently the focus of much attention in the topical areas of storage of hydrogen,${ }^{[5]}$ methane, or carbon dioxide $\left.{ }^{[6]}\right)$, the functionalization of organic linkers (either pre- or post-synthesis) may allow tuning of the porosity, reactivity, and the selectivity towards binding of guest molecules, ${ }^{[7-9]}$ and the use of chiral ligands may result in chiral framework materials. ${ }^{[10,11]}$ In addition, MOF structures also often show great flexibility in the solid state, giving them properties distinct from the traditional inorganic zeotype materials. ${ }^{[12-14]}$

To explore the extent to which new MOF materials may be "designed" it is now important to elucidate the fundamental physico-chemical details of the crystallization of MOF

[*] Dr. F. Millange, Dr. M. I. Medina, Dr. N. Guillou, Prof. G. Férey Institut Lavoisier, Université de Versailles UMR 8180, 78035 Versailles (France)

E-mail: franck.millange@uvsq.fr

K. M. Golden, Dr. R. I. Walton

Department of Chemistry, University of Warwick

Coventry, CV4 7AL (UK)

E-mail: r.i.walton@warwick.ac.uk

[**; We thank DESY for provision of beamtime at HASYLAB, and we are grateful to the group of Prof. Dr. W. Bensch of the ChristianAlbrechts-Universität zu Kiel, in particular Beatrix Seidlhofer and Elena Antonova, for their assistance with use of Beamline F3 and the loan of their heating device. The ESRF provided beamtime on ID31 and we thank Dr. I. Margiolaki and Dr. A. Fitch for their assistance with measuring data there. We are grateful to Nikos Kourkoumelis, University of Ioannina, for modifying his PowDLL program to allow analysis of the EDXRD data. This work was supported by CNRS and French ANR "CONDMOFs" funding. Supporting information for this article is available on the WWW under http://dx.doi.org/10.1002/anie.200905627. materials: knowledge of how complex extended network structures are assembled from simple chemical precursors in solution could ultimately permit some fine tuning of synthesis conditions to test and realize the ideas of design in synthesis. ${ }^{[15]}$ Only a few such studies have been reported to date. These include extended X-ray absorption fine structure (EXAFS) spectroscopy studies of reactive solutions to examine the presence of structural building units in solution, through the amorphous intermediate to final crystalline product; ${ }^{[16]}$ light scattering from clear solutions to observe the formation of colloidal nanocrystals $;^{[17,18]}$ and mass spectrometry to examine the interaction of $\mathrm{Mg}^{2+}$ ions with (+)camphoric acid to identify possible building units for the construction of a MOF. ${ }^{[19]}$ Shoaee et al. recently used atomic force microscopy (AFM) to examine a growing face of a copper MOF after injection of a reactive solution and suggested that the growth unit from solution was actually smaller than the paddle-wheel-shaped building unit identified in its crystal structure. ${ }^{[20]}$ The study of MOF crystallization mechanism has so far been concerned with the local structure of solution species prior to the appearance of crystal order, but it is important to examine crystal growth over all length scales to build up a complete picture of crystallization. Herein, we describe observations of the emergence of the crystal order of MOFs from reactive solutions, above room temperature, by using the time-resolved energy-dispersive $\mathrm{X}$ ray diffraction (EDXRD) method for two established transition-metal carboxylate MOFs. The technique has been used successfully for the in situ study of the crystallization of a variety of inorganic materials, ${ }^{[21-26]}$ although to date it has not been applied to the study of hybrid MOF materials. Its advantage lies in the use of high intensity white beam X-rays, which allows the non-invasive penetration of laboratory-scale reaction vessels under elevated temperature and autogeneous pressure. Thus the evolution of Bragg peaks as a function of reaction conditions and time can be monitored with a time resolution of less than $1 \mathrm{~min}$.

Time-resolved EDXRD measurements were made on Beamline F3 of the HASYLAB facility (DESY, Hamburg, Germany). The first system we studied was the copper(II) benzene tricarboxylate HKUST-1, [ $\mathrm{Cu}_{3}(\mathrm{BTC})_{2}$-solvent] (where $\mathrm{BTC}=1,3,5$-benzene-tri-carboxylate, and the framework contains occluded solvent in its as-made form) ${ }^{[27]}$ This phase crystallizes under solvothermal conditions from a clear solution prepared by dissolving copper(II) nitrate hemi(pentahydrate) and trimesic acid in a mixture of water, ethanol, and DMF, within a sealed quartz vessel. Figure 1 shows a surface plot of diffraction data during the crystallization of the material at $125^{\circ} \mathrm{C}$. A series of Bragg peaks, all 

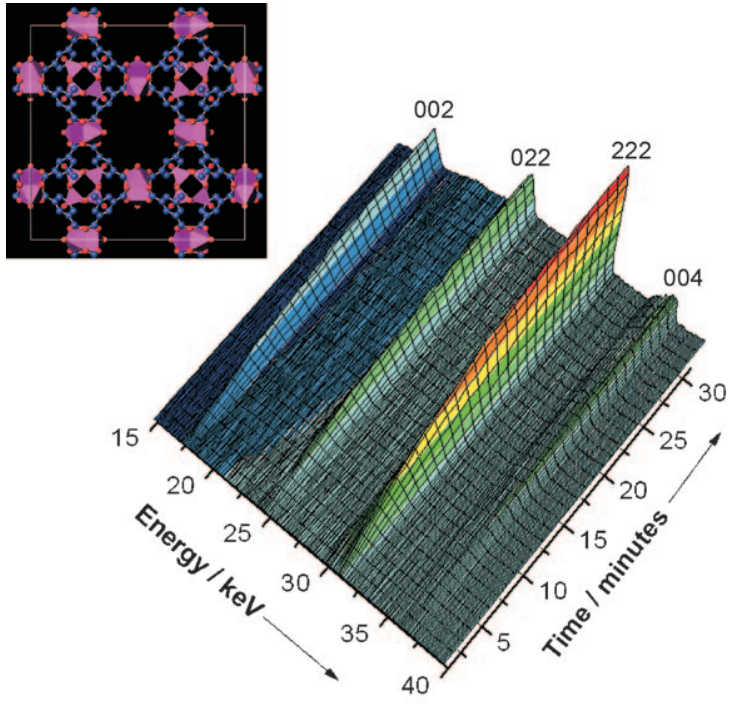

Figure 1. Time-resolved in situ EDXRD data measured during the crystallization of the copper carboxylate HKUST- 1 at $125^{\circ} \mathrm{C}$. The Bragg peaks are indexed on an F-centered cubic unit cell with $a=26.34 \AA$. Inset: view of the structure of HKUST-1 with five-coordinate $\mathrm{Cu}$ as pink polyhedra, blue $\mathrm{C}$, red $\mathrm{O}$.

indexed on the expected $F m \overline{3} m$ cubic unit cell ${ }^{[27]}$ (with $a=$ $26.34 \AA$ ), appear simultaneously after no detectable induction period and grow to their maximum intensity in around $30 \mathrm{~min}$. The in situ study was repeated at five temperatures to obtain information about the kinetics of the crystallization: Figure 2 shows normalized crystallization curves produced by integration of the most intense (222) Bragg peak at each temperature. (Integration of all the Bragg peaks was performed and the crystallization curves from each were superimposable; see Supporting Information.) Analysis of the crystallization curves was performed using the Avrami-Erofe'ev model by

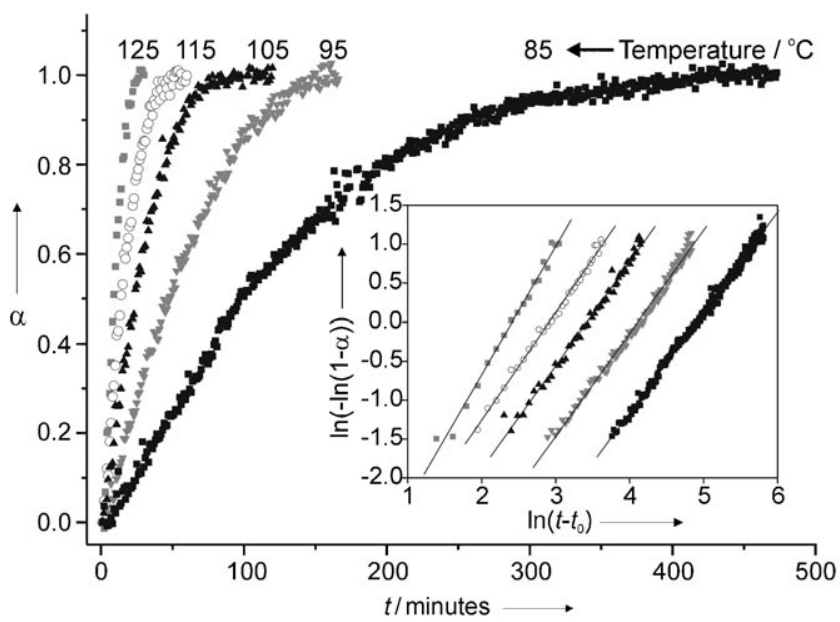

Figure 2. Kinetic analysis of the crystallization of HUKST-1: plot of extent of crystallization $(\alpha)$ curves against time $(t)$ obtained by integration of the 222 Bragg peak in the EDXRD data. Inset: analysis by the method of Sharp and Hancock to test fitting to the Avrami-Erofe'ev nucleation-growth crystallization model $\alpha=1-\exp \left\{-\left(k\left(t-t_{0}\right)\right)^{n}\right\}$ with lines that are the result of linear regression analysis. the method of Sharp and Hancock ${ }^{[28]}$ (Figure 2). Although this kinetic model is empirical in nature, it has been widely applied to situations where a nucleation-growth process is expected from a homogeneous medium, such as crystallization from a solution or gel, and it allows rate constants to be extracted and compared when reactions conditions are varied. ${ }^{[2]}$ The value of $n$, the Avrami exponent, is believed to give some indication of the mechanism of crystallization, in particular the balance of the rates of nucleation versus crystal growth. We observe values of $n$ close to 1.5 (Supporting Information) suggesting that crystallization is controlled largely by the formation of nucleation sites, rather than diffusion of reactive species to the sites or crystal growth itself at the sites. Zacher et al. studied the earliest stage of HKUST1 formation using light scattering ${ }^{[18]}$ and also concluded that crystallization was dominated by homogeneous nucleation and growth, with nucleation extending over the time-scale of their experiment (up to $30 \mathrm{~min}$ ). It is also noteworthy that the initial formation of nucleation sites is effectively instantaneous at all the temperatures studied, with no observation of an induction time, yet it is the continued formation of nucleation sites that dominates the crystallization rate. Similar Avrami exponents have been found in the solution crystallization of other inorganic materials, for example, the liquid-phase reconstruction of layered hydroxides from amorphous oxides, ${ }^{[30]}$ the hydrothermal crystallization of barium titanate, ${ }^{[31]}$ and the formation of mixed tungstenmolybdenum oxides. ${ }^{[32]}$ In the case of silicate zeolites, values of $n>2$ have typically been reported, but the difference is that zeolites often crystallize from viscous gels rather than from clear solutions. ${ }^{[24,33]}$ An Arrhenius plot (Supporting Information), gave an activation energy of $73.3 \mathrm{~kJ} \mathrm{~mol}^{-1}$. This value is larger, yet comparable, to the nucleation-controlled crystal growth of other types of inorganic solids from hydrothermal solutions, such as barium titanate $\left(55 \mathrm{~kJ} \mathrm{~mol}^{-1}\right)^{[31]}$ and $\mathrm{Mg}-\mathrm{Al}$ hydroxide $\left(41 \mathrm{~kJ} \mathrm{~mol}^{-1}\right){ }^{[30]}$

The second system we studied was the iron(III) terephthalate with the MIL-53 structure, $\left[\mathrm{Fe}^{\mathrm{III}}(\mathrm{OH}, \mathrm{F})\left\{\mathrm{O}_{2} \mathrm{C}-\mathrm{C}_{6} \mathrm{H}_{4^{-}}\right.\right.$ $\left.\left.\mathrm{CO}_{2}\right\} \cdot \mathrm{H}_{2} \mathrm{O}\right] \cdot{ }^{[34]}$ This material has a one-dimensional channel system made up of trans linked octahedral Fe units, crosslinked by the dicarboxylate. Crystallization of MIL-53 takes place from a clear solution produced by dissolving iron(III) chloride hexahydrate, terephthalic acid, and hydrofluoric acid in DMF heated at atmospheric pressure under reflux. Figure 3 shows 3D plots of time-resolved EDXRD data measured at $150^{\circ} \mathrm{C}$ : the ultimate product is the expected MIL-53 but its crystallization is preceded by the transient appearance of another crystalline phase. If the temperature is lowered to $125^{\circ} \mathrm{C}$ the intermediate phase has a longer lifetime and at $100^{\circ} \mathrm{C}$ it is the sole product after $6 \mathrm{~h}$, although on extended heating the expected MIL-53 product is eventually found. Quenching experiments allowed the intermediate to be isolated as a highly crystalline powder suitable for structure elucidation by high-resolution powder diffraction (see Supporting Information). This analysis reveals that the intermediate material is related to a previously reported phase, MOF- $235,{ }^{[35]}$ in which trimers of iron(III) oxy-octahedra are linked by terephthalate ligands, and trapped within the porous three-dimensional network are not only DMF solvent 


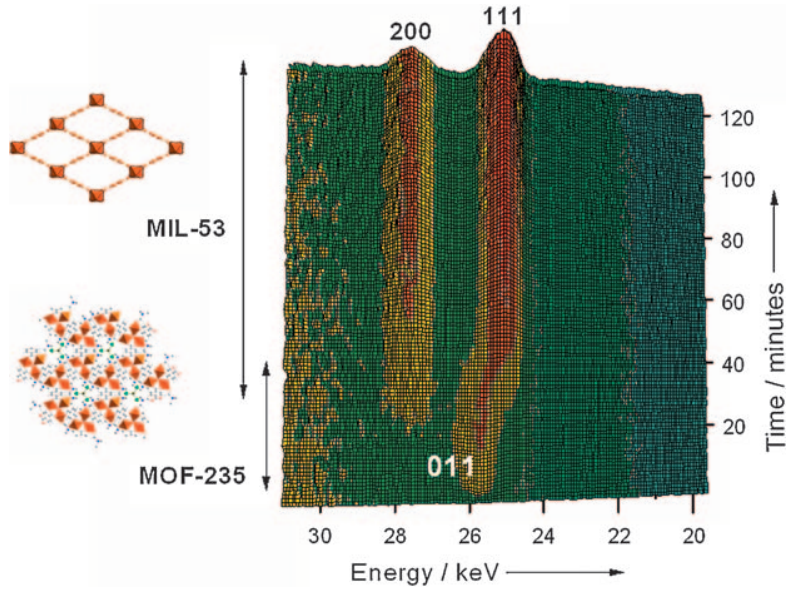

Figure 3. Time-resolved EDXRD measured during the crystallization of MIL-53 at $150^{\circ} \mathrm{C}$, with a crystalline transient phase seen at short reaction times.

molecules but also $\mathrm{FeCl}_{4}^{-}$anions that balance the positive charge of the MOF framework (Figure 4). The topology of this intermediate is unrelated to the final MIL-53 product,

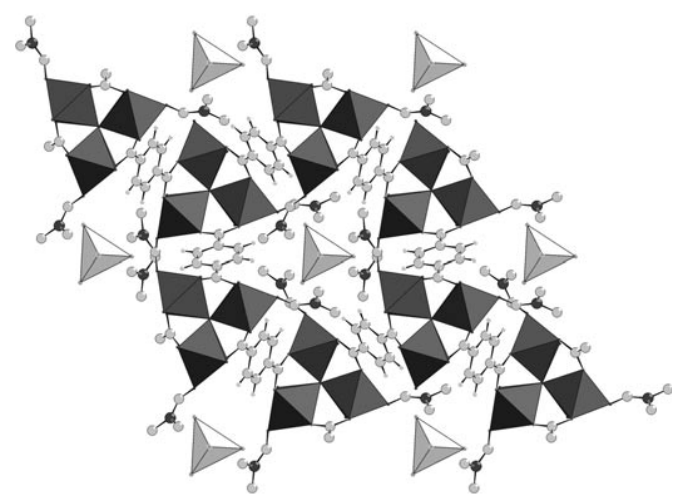

Figure 4. A view of the structure of transient intermediate phase seen during MIL-53 crystallization, isolated by quenching. The MOF framework is constructed from trimers of iron(III) octahedra linked by terephthalate linkers (ball-and-stick model) and contains occluded $\mathrm{FeCl}_{4}{ }^{-}$tetrahedral units. Extra-framework solvent molecules have been omitted for clarity. This is a projection viewed along the $c$ axis.

indeed the building units of the structure are completely different, which suggests that the conversion of one into another is most unlikely to occur by a solid-state rearrangement: it is probable that the first phase dissolves, releasing reactive solution species for crystallization of the final product.

In summary, for two transition-metal carboxylate MOFs we see two distinct solvothermal crystallization scenarios: classical nucleation-growth kinetics from solution, or crystallization via a metastable precursor. This illustrates the complexity of MOF crystallizations and shows how in situ measurements are crucial for a further understanding of their synthesis. These measurements would be of great benefit in the study of more complex MOF systems; for example, in understanding the competitive formation of several phases, studying the effect of ligand modification, and for efficiently assessing reaction conditions (solvent, $\mathrm{pH}$, temperature etc.) for the discovery of new materials, as well as allowing some deeper physical understanding of how the complex solids are formed. Future work must also include the development of better kinetic models, which relate to the chemical transformations actually taking place during crystallization, ${ }^{[29]}$ and also the use of combined techniques for following crystallization over several length scales simultaneously. ${ }^{[26,32]}$

Received: October 7, 2009

Published online: December 16, 2009

Keywords: crystal growth - metal-organic frameworks . structure elucidation $\cdot \mathrm{X}$-ray diffraction - zeolite analogues

[1] For an introduction to the fast-developing area of MOF chemistry see a special issue of Chemical Society Reviews published in 2009 (Volume 38, Issue 5): J. R. Long, O. M. Yaghi, Chem. Soc. Rev. 2009, 38, 1213.

[2] D. J. Tranchemontagne, J. L. Mendoza-Cortés, M. O'Keeffe, O. M. Yaghi, Chem. Soc. Rev. 2009, 38, 1257.

[3] J. J. Perry IV, J. A. Perman, M. J. Zaworotko, Chem. Soc. Rev. 2009, 38, 1400.

[4] A. U. Czaja, N. Trukhan, U. Müller, Chem. Soc. Rev. 2009, 38, 1284.

[5] L. J. Murray, M. Dincă, J. R. Long, Chem. Soc. Rev. 2009, 38, 1294.

[6] J.-R. Li, R. J. Kuppler, H.-C. Zhou, Chem. Soc. Rev. 2009, 38, 1477.

[7] R. A. Fischer, C. Woll, Angew. Chem. 2008, 120, 8285; Angew. Chem. Int. Ed. 2008, 47, 8164.

[8] K. K. Tanabe, S. M. Cohen, Angew. Chem. 2009, 121, 7560; Angew. Chem. Int. Ed. 2009, 48, 7424.

[9] D. Farrusseng, S. Aguado, C. Pinel, Angew. Chem. 2009, 121, 7638; Angew. Chem. Int. Ed. 2009, 48, 7502.

[10] D. Bradshaw, J. B. Claridge, E. J. Cussen, T. J. Prior, M. J. Rosseinsky, Acc. Chem. Res. 2005, 38, 273.

[11] C. Livage, N. Guillou, P. Rabu, P. Pattison, J. Marrot, G. Férey, Chem. Commun. 2009, 4551.

[12] C. Serre, F. Millange, C. Thouvenot, M. Nogues, G. Marsolier, D. Louer, G. Férey, J. Am. Chem. Soc. 2002, 124, 13519.

[13] S. Kitagawa, K. Uemura, Chem. Soc. Rev. 2005, 34, 109.

[14] F. Millange, C. Serre, N. Guillou, G. Férey, R. I. Walton, Angew. Chem. 2008, 120, 4168; Angew. Chem. Int. Ed. 2008, 47, 4100.

[15] R. E. Morris, ChemPhysChem 2009, 10, 327.

[16] S. Surblé, F. Millange, C. Serre, G. Férey, R. I. Walton, Chem. Commun. 2006, 1518.

[17] S. Hermes, T. Witte, T. Hikov, D. Zacher, S. Bahnmuller, G. Langstein, K. Huber, R. A. Fischer, J. Am. Chem. Soc. 2007, 129, 5324.

[18] D. Zacher, J. N. Liu, K. Huber, R. A. Fischer, Chem. Commun. 2009, 1031.

[19] J. A. Rood, W. C. Boggess, B. C. Noll, K. W. Henderson, J. Am. Chem. Soc. 2007, 129, 13675.

[20] M. Shoaee, M. W. Anderson, M. R. Attfield, Angew. Chem. 2008, 120, 8653; Angew. Chem. Int. Ed. 2008, 47, 8525.

[21] J. Munn, P. Barnes, D. Hausermann, S. A. Axon, J. Klinowski, Phase Transitions 1992, 39, 129.

[22] R. J. Francis, S. J. Price, J. S. O. Evans, S. O'Brien, D. O'Hare, S. M. Clark, Chem. Mater. 1996, 8, 2102. 


\section{Communications}

[23] R. I. Walton, T. Loiseau, D. O’Hare, G. Férey, Chem. Mater. 1999, 11, 3201 .

[24] R. I. Walton, F. Millange, D. O'Hare, A. T. Davies, G. Sankar, C. R. A. Catlow, J. Phys. Chem. B 2001, 105, 83.

[25] R. Kiebach, N. Pienack, M. E. Ordolff, F. Studt, W. Bensch, Chem. Mater. 2006, 18, 1196.

[26] G. Sankar, T. Okubo, W. Fan, F. Meneau, Faraday Discuss. 2007, $136,157$.

[27] S. S. Y. Chui, S. M. F. Lo, J. P. H. Charmant, A. G. Orpen, I. D. Williams, Science 1999, 283, 1148.

[28] J. D. Sharp, J. H. Hancock, J. Am. Ceram. Soc. 1972, 55, 74.

[29] E. E. Finney, R. G. Finke, Chem. Mater. 2009, 21, 4692.
[30] F. Millange, R. I. Walton, D. O'Hare, J. Mater. Chem. 2000, 10, 1713.

[31] R. I. Walton, F. Millange, R. I. Smith, T. C. Hansen, D. O'Hare, J. Am. Chem. Soc. 2001, 123, 12547.

[32] R. Kiebach, N. Pienack, W. Bensch, J. D. Grunwaldt, A. Michailovski, A. Baiker, T. Fox, Y. Zhou, G. R. Patzke, Chem. Mater. 2008, 20, 3022.

[33] A. T. Davies, G. Sankar, C. R. A. Catlow, S. M. Clark, J. Phys. Chem. B 1997, 101, 10115.

[34] F. Millange, N. Guillou, R. I. Walton, J. Grenèche, I. Margiolaki, G. Férey, Chem. Commun. 2008, 4732.

[35] A. C. Sudik, A. P. Cote, O. M. Yaghi, Inorg. Chem. 2005, 44, 2998. 